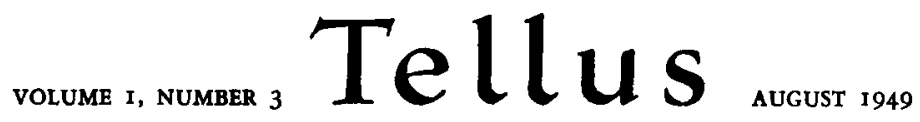

A QUARTERLY JOURNAL OF GEOPHYSICS

\title{
Isostasy and its Meaning
}

By B. GUTENBERG, California Institute of Technology ${ }^{1}$

(Manuscript received June 25, 1949)

\begin{abstract}
The theory of isostasy supposes that, in regions which have not been disturbed recently, each vertical column of the earth's crust with a certain minimum radius and extending to a depth of about $100 \mathrm{~km}$ has approximately the same mass. To find the deviation from this approximation in a given region, the density must be assumed as a function of depth. Such assumptions used at present for calculations are discussed critically. The resulting errors are greater than it is normally beleaved; errors in the calculated isostatic gravity anomalies exceeding ten milligals must be expected in certain regions. Systematic errors result from the usual assumption in routine calculations that the mean density in the earth's crustal layers under the bottom of the Pacific and in the continental areas is the same, and that in both the difference between the density of the layers above about $30 \mathrm{~km}$ and the layers below this depth is 0.6 . The processes producing and maintaining isostatic equilibrium are discussed.
\end{abstract}

In the theory of isostasy it is assumed that in regions that have not been disturbed recently each vertical column of the earth's crust with a given radius (at least, say, Io $\mathrm{km}$ ) and extending down to a sufficient specified depth (apparently at least $60 \mathrm{~km}$ ), has approximately the same mass, regardless of the surface condition (continental or oceanic) or of the surface elevation of the region. Since this hypothesis is an approximation, the question cannot be raised whether the theory of isostasy is true or false, but how good the approximation is in a given region.

In addition to the use of deflections of the vertical, for which too few observations are

1 Contribution No. 504, California Institute of Technology, Division of the Geological Sciences, Pasadena, California. available, there are two ways to approach this question. The first is, to use observations of the density and distribution of rocks in the earth's crust and of gravity at the earth's surface and to calculate the residuals (the so-called gravity anomalies) against an assumed equilibrium condition; the second is to consider the processes involved in establishing isostasy. Neither provides an answer with the desired precision, since each requires certain assumptions which are not as well founded as is commonly believed.

For the first approach it is necessary to observe gravity at as large a number of points on the earth's surface as possible, and to calculate under various assumptions regarding the structure of the earth's crust their deviation from gravity values theoretically to be ex- 
pected, if hydrostatic equilibrium exists at an assumed depth. Thus, these calculations must be based on hypotheses regarding the density in the various crustal layers as well as on the thickness of these layers. Two fundamental hypotheses have been used which are based on two extreme assumptions (for historical references, see e.g. BowIE I93I). For the first, Pratt supposed that all crustal columns begin at a discontinuity which has the same depth for the whole earth, that within each such column the density is constant, and that the differences in elevations of the earth's crust are compensated by different densities in the various crustal columns. The assumed discontinuity is called "depth of compensation". The product of the density $d$ of the column and the surface elevation $h$ above the depth of compensation is the same everywhere:

$$
d h=\text { constant }
$$

The other extreme assumption is that of AIRY who assumed that all blocks near the surface have the same density and "float" in the deeper material, like icebergs are floating in water. If we denote by $d_{\mathrm{r}}$ the density of the deeper material in which the crust is floating, by $d_{2}$ the density of the floating material, by $h_{\mathrm{I}}$ the distance of the bottom of the floating material from an arbitrary depth, which must be at or below the level of the deepest part of the floating material, and by $h_{2}$ the thickness of the floating material, then the AIRY hypothesis can be expressed by the following equation:

$$
d_{1} h_{1}+d_{2} h_{2}=\text { constant }
$$

AIry assumed that $d_{1}$ and $d_{2}$ do not depend on the locality under consideration but locally different values of $d_{2}$ are indicated by the observations (Table I) and are to be expected for geophysical reasons.

In addition to his idea concerning the mechanism by which isostasy is maintained, (but not as a prerequisite to it), Pratr assumed that the difference in density in the various parts of the earth's crust depends on the amount of contraction at the time when the material solidified, thus explaining the smaller density of high mountain areas. This idea of PratT is generally considered as incorrect. On the other hand, in the AIRY theory it must be assumed that there is sufficient "plasticity" somewhere in the outer part of the earth to make "isostatic" adjustment possible.

There can be little doubt that neither the PRATT nor the AIRY hypothesis is completely accurate. In most regions the actual conditions are probably better approximated by the Airy hypothesis than by Pratt's. (See GutenBERG I927 and HeIskanen 1936). The condition for isostasy is approximately given by

$$
\int_{0}^{h} d d z=\text { constant }
$$

regardless of the locality; the density $d$ is a function of the depth, different from region to region, $z$ is the elevation above a level at which approximately hydrostatic equilibrium can be assumed, say about $100 \mathrm{~km}$ below sea level, and $h$ is the value of $z$ at the earth's surface.

There have been various ways by which the mechanism of isostasy and the deviations of the actual from assumed ideal conditions have been investigated. In the early attempts (see e. g. Heiskanen 1936) it had been believed that the best approximation to the actual conditions could be found by assuming a variety of density distributions and calculating the resulting gravity anomalies; that assumption was considered the most likely, which gave the smallest anomalies. More recently (HEISKANEN I948) the assumption has been considered best which gives the least effect of elevation on the residuals in a given area. Finally, Heiskanen (1936) calculated residuals assuming the probable thickness of the layers as they have been found from seismological evidence and combining them with probable values of the density in these layers. This type of reduction, which is occasionally referred to as "Heiskankn method", certainly is preferable to any other. Unfortunately, it requires a large amount of work for the calculations.

Recently the tendency prevails to use still more uniform assumptions for the whole earth and to apply them to routine reductions of the fast increasing body of data, rather than make for each region such individual assumptions which seem to be most probable for the local tectonic structure down to a depth of at least $60 \mathrm{~km}$. Thus, it has been proposed recently (HeisKanEN I948 a) to use not only the 
same mean densities of 2.67 for the upper layers, and of 3.27 for the "sima" regardless of the crustal structure-continental, Atlantic or Pacific-but, in addition, to suppose everywhere the same "thickness of the crust" of $30 \mathrm{~km}$ (corresponding to a region where the surface is at sea level). If this suggestion is carried out, a faster calculation of "isostatic gravity anomalies" will be possible, and outlines of areas with large anomalies will become available more speedily; however, increased errors in the calculated anomalies must be expected. Conclusions based on differences of the order of ro milligals, especially in comparing values in oceanic areas with those in continental regions must be expected to become even more doubtful than at present; unnecessary great uncertainties in the calculated isostatic gravity anomalies result from supposing everywhere densities of 2.67 and 3.27 in the "floating" and "supporting" layers respectively, regardless of the tectonic structure in the region involved. There is little doubt that the density of the surface layers in the continents is noticeably smaller than that of the corresponding crustal layers in the oceans. Data, according to Washington (1922), are given in Table I.

Table I

Average densities according to WASHINGTON $a$ without, $b$ with water content, $n$ number of analyses.

\begin{tabular}{|c|c|c|c|}
\hline \multirow{2}{*}{ Region } & \multicolumn{2}{|c|}{ Average density } & \multirow{2}{*}{$n$} \\
\hline & $a$ & $b$ & \\
\hline North America. & 2.78 & 2.73 & $I, 709$ \\
\hline South America. & 2.78 & 2.73 & 138 \\
\hline Europe $\ldots \ldots$. & 2.79 & 2.73 & $1,98_{5}$ \\
\hline Africa $\ldots \ldots \ldots$ & 2.78 & 2.72 & 223 \\
\hline Australia ... & 2,81 & 2.75 & 287 \\
\hline Atlantic ... & 2.89 & $2.8 \mathrm{I}$ & $5^{6}$ \\
\hline Pacific........ & 3.09 & 3.01 & 72 \\
\hline
\end{tabular}

Table I shows, in addition, that in all probability, even in the continents, the density assumed for the crustal layers is too small, considering the fact that values assumed for the gravity calculations have to represent not only the density of the uppermost surface layers, but also of the deeper more basic and heavier layers down to the material in which the upper layers are "floating". Their approximate thickness is given in the last column of Table II.
Table II

Average thickness of layers in the earth's crust with a given velocity of longitudinal earthquake waves (all data approximate with relatively large local variations).

\begin{tabular}{|c|c|c|c|}
\hline \multirow[b]{2}{*}{ Region } & \multicolumn{3}{|c|}{$\begin{array}{l}\text { Thickness of layers, including } \\
\text { sediments, in } \mathrm{km}\end{array}$} \\
\hline & $\begin{array}{c}\text { With ve } \\
\text { longitudina } \\
5^{1} / 2-6^{1} / 4 \\
\mathrm{~km} / \mathrm{sec}\end{array}$ & $\begin{array}{l}\text { ocity of } \\
\text { waves of } \\
6^{1} / 4-7^{3} / 4 \\
\mathrm{~km} / \mathrm{sec} \text {. }\end{array}$ & $\begin{array}{c}\text { Both } \\
\text { combined }\end{array}$ \\
\hline Northwest Europe & 27 & small? & 27 \\
\hline Black Forest .... & 16 & I6 & 32 \\
\hline Central Alps .... & 30 & 25 & 55 \\
\hline $\begin{array}{l}\text { Central Asia .... } \\
\text { Southern California }\end{array}$ & 30 & 20 & 50 \\
\hline $\begin{array}{c}\text { coastal. . . . . . } \\
\text { Central California }\end{array}$ & 18 & I 8 & 36 \\
\hline coastal. . . . . . & Io & 22 & 32 \\
\hline $\begin{array}{l}\text { Sierra Nevada ... } \\
\text { Eastern North }\end{array}$ & 20 & $4^{\circ}$ & 60 \\
\hline America ..... & IO & 30 & $4^{\circ}$ \\
\hline $\begin{array}{l}\text { New Zealand.... } \\
\text { Atlantic Ocean .. }\end{array}$ & $\begin{array}{c}\text { I2 } \\
\text { sediments ? }\end{array}$ & $\begin{array}{l}18 \\
20 ?\end{array}$ & $\begin{array}{l}30 \\
20 ?\end{array}$ \\
\hline Pacific Ocean.... & sediments? & small? & small? \\
\hline
\end{tabular}

The density of rocks in these layers, as determined from laboratory samples under pressure of I atmosphere, varies from about 2.65 in granites, 2.7 in granodiorites and also in the Basement Complex in Finland, to 3.0 in gabbro, which by many is considered characteristic for the deeper layers of the "floating" material. The densities of rocks which are possibly characteristic of the layer "supporting" the crust, such as peridotite, pyroxenite and dunite, are about 3.2 to 3.3. Thus, in the continental areas, the difference in density between the "floating" and "supporting" material may well be only $2 / 3$ of the difference of 0.6 , which is assumed for practically all gravity calculations, and still less in areas with "Pacific structure". The effect of pressure on the density can be assumed to be the same for both layers, as a first approximation.

It does not seem unlikely that the assumption of a difference in density of the two layers of 0.6 throughout the world results in systematic errors which affect especially calculations of gravity anomalies for the oceans. This may well be one of the reasons for the finding from gravity observations that the equator can be represented in second approximation by an ellipse with the short 
and long axes pointing towards the continental and oceanic areas of the earth's crust respectively and differing by roughly 300 meters.

As a consequence of the inaccuries of the assumptions, the calculation of isostatic gravity that in the earth's crust the relaxation time, that is the time during which a given deviation from equilibrium is reduced to $\mathrm{r} / \mathrm{e}$ by flow processes, is of the order of 10,000 years. No exact figure can be given for specific layers, especially since the effect of the crustal

Table III

Isostatic gravity anomalies $\Delta g$ in milligal after HEISKANEN (1936).

a) Using PRATT'S reduction method, depth of compensation $T \mathbf{k m}$.

b) AIRY'S method, "thickness of the crust" $D$ km.

c) HEISKANEN'S method, using geophysically determined data on the crustal layers.

\begin{tabular}{|c|c|c|c|c|c|c|c|c|c|}
\hline \multirow{3}{*}{ Region } & \multicolumn{9}{|c|}{ Method of reduction } \\
\hline & \multicolumn{2}{|c|}{$a$} & \multicolumn{2}{|c|}{$a$} & \multicolumn{2}{|c|}{$b$} & \multicolumn{2}{|c|}{$b$} & \multirow{2}{*}{$\frac{c}{\Delta g}$} \\
\hline & $\Delta g$ & $T$ & $\Delta g$ & $T$ & $\Delta g$ & $D$ & $\Delta g$ & $D$ & \\
\hline 87 stations in plains, USA . . . . & +8 & $85 \cdot 3$ & +7 & II 3.7 & +6 & 60 & +4 & 40 & +4 \\
\hline 20 mountain stations, USA. & $+\mathbf{I} 8$ & $85 \cdot 3$ & +9 & 113.7 & - Io & 77 & + II & 40 & +6 \\
\hline 27 coastal stations, USA $\ldots \ldots \ldots$ & +3 & $85 \cdot 3$ & $-I$ & 113.7 & -4 & 77 & +4 & 40 & $-\mathbf{I}$ \\
\hline 23 coastal stations, Pacific, USA.. & & & -20 & 113.7 & -20 & 60 & -18 & $4^{\circ}$ & -15 \\
\hline I 2 stations, Caucasus & +47 & $\mathbf{I}_{5} 6.3$ & $+6 \mathbf{I}$ & 113.7 & +28 & 77 & $+3^{8}$ & 64 & \\
\hline Io stations, Alps .. & +31 & $85 \cdot 3$ & +18 & $\mathbf{1} 3.7$ & $-\mathrm{I}_{4}$ & 77 & & 40 & \\
\hline
\end{tabular}

anomalies involves errors which are far greater than the errors in the observations. Gravity observations frequently are accurate to better than I milligal. On the other hand, under favorable circumstances the calculated gravity anomalies may be uncertain by 10 milligals or more, especially in mountain areas. Table III gives selected data after HEISKANEN (1936). Still greater differences are to be found in his tabulations for more extreme values of the supposed depth of compensation; in addition, the anomalies calculated by the AIRY method correspond to the same mean density of the surface layers everywhere, and other assumptions will increase the differences between the results.

The belts of large negative and large positive anomalies stand out regardless of the method of reduction under reasonable assumptions. These belts of large gravity anomalies coincide almost everywhere with belts of earthquakes (Gutenberg and Richter I949). There is no doubt that they are actually regions in which tectonic processes are going on, disturbing continuously the isostatic equilibrium. There is some indication from the post-glacial uplift layers on this process is not known well enough. However, since deep focus earthquakes occur down to a depth of about $700 \mathrm{~km}$, strain must be able to accumulate down to this depth; and the relaxation time in these layers must be expected to be at least of the order of roo years. It may well be that at a depth of about $700 \mathrm{~km}$, the relaxation time falls below the critical limit at which flow processes become so fast that they prevent accumulation of strain large enough to produce a break.

The speed of flow-processes is frequently, characterized by the "coefficient of viscosity" $\eta$, defined by

$$
\eta=\mu \tau
$$

where $\mu$ is the coefficient of rigidity (about $5 \times$ IO $^{11}$ dynes $/ \mathrm{cm}^{2}$ in the layers under consideration) and $\tau$ the time of relaxation. The coefficient of viscosity corresponding to a time of relaxation of 10,000 and 100 years is consequently of the order of $1^{23}$ and $\mathrm{IO}^{2 \mathrm{I}}$ poises respectively. It cannot be appreciably below the latter value at depths down to 
$700 \mathrm{~km}$, if the hypotheses involved in the preceding calculations are correct.

The second method for investigating the mechanism of isostasy is to consider the structures and the processes involved. In Table II a summary is given of the approximate thickness of layers in several regions from seismic data published by various seismologists. On the other hand, results found from isostatic calculations (Herskanen 1948 a, 1948 b) indicate that the "thickness of the crust" for a region with the surface at sea level is in general about $30 \mathrm{~km}$ and at greater depth under mountain ranges. The combined results can be interpreted as meaning that down to a depth of at least $60 \mathrm{~km}$ there are relatively large differences in density between the various parts of the earth. This does not mean necessarily that contemporary flow processes within this depth range produce approximate equilibrium. At present, noticeable flow processes may be limited to distinctly greater depths. It must be considered that the speed of flow-processes in a given region was probably appreciable higher at times when mountains were forming there under much greater stresses and higher temperatures than today, and that probably the "roots of mountains" originated simultaneously with the mountains.

Unfortunately, our theoretical knowledge of flow processes in the interior of the earth is practically nil. At present there is no theory available which applies to such processes. All that is known are results of a relatively few experiments on rock under high pressures or temperatures (rarely both), which have led to empirical descriptions of such processes. The "constants" involved are functions of time and a variety of physical conditions. Processes at the surface of the earth, which are rather slow compared with the time of relaxation of roughly I0,000 years, such as sedimentation and erosion, do not lead to large gravity anomalies or deviations from equilibrium. Where processes have a much higher speed, gravity anomalies must be expected, and vice-versa. If these processes stop, as, for example, in melting of ice or accumulation of ice in glaciated areas, these areas gradually approach hydrostatic equilibrium again.

The earth's crust as a whole is not in hydrostatic equilibrium. However, there is no doubt that there are large tectonically quiet areas in which the material at a depth of about $100 \mathrm{~km}$ is not very far from hydrostatic equilibrium. The combination of these facts is what we call "isostasy". One of our major aims must be to find deviations from hydrostatic equilibrium in the various regions of the earth with much higher accuracy than at present.

\section{REFERENCES}

Bowie, W., I 93 I : Isostasy. Physics of the earth, vol. 2, Nat. Res. Council, Washington, D. C., No. 78 , pp. 103-IIs.

GutenberG, B., I927: Die Bedeutung der Isostasie. Gerlands Beitr. 2. Geophysik, 16: pp. 396-403.

Gutenberg, B. and Richter, C. F., 1949: Seismicity of the Farth and Associated Phenomena. Princeton Press.

Heiskanen, W., 1936: Das Problem der Isostasie. Handbuch der Geophysik, vol. I, pp. 878-95I. Berlin.
HeISKANEN. W., I 948 a: Report on Isostasy. Iniern. Union of Geophys. and Geod., Oslo.

- 1948 b: Lectures at Pasadena, December 1948. See also: On the interpretation of the gravity anomalies. Geol. Soc. Amer. Bull., (in press).

Meinesz, Vening F. A., 1933: Ergebnisse der Schwerkraftbeobachtungen auf dem Meere in den Jahren 1923-1932. Ergebnisse der Kosmischen Physik, 2: pp. I53-212.

WAshington, H., I922: Isostasy and rock density. Geol. Soc. Amer. Bull, 23: pp. 372-410. 